\title{
Remote sensing of fish-processing in the Sundarbans Reserve Forest, Bangladesh: an insight into the modern slavery-environment nexus in the coastal fringe
}

\author{
Bethany Jackson ${ }^{1,2}$ (D) Doreen S. Boyd ${ }^{1,2} \cdot$ Christopher D. Ives $^{1,2} \cdot$ Jessica L. Decker Sparks ${ }^{2} \cdot$ Giles M. Foody $^{1,2} \cdot$ \\ Stuart Marsh ${ }^{3} \cdot$ Kevin Bales ${ }^{2,4}$
}

Received: 14 February 2020 / Accepted: 1 September 2020 / Published online: 17 September 2020

(C) The Author(s) 2020

\begin{abstract}
Land-based fish-processing activities in coastal fringe areas and their social-ecological impacts have often been overlooked by marine scientists and antislavery groups. Using remote sensing methods, the location and impacts of fish-processing activities were assessed within a case study of Bangladesh's Sundarbans mangrove forests. Ten fish-processing camps were identified, with some occurring in locations where human activity is banned. Environmental degradation included the removal of mangroves, erosion, and the destruction of protected areas. Previous studies have identified cases of labour exploitation and modern slavery occurring within the Sundarbans, and remote sensing was used to triangulate these claims by providing spatial and temporal analysis to increase the understanding of the operational trends at these locations. These findings were linked to the cyclical relationship between modern slavery and environmental degradation, whereby environmental damage is both a driver and result of workers subjected to modern slavery. Remote sensing can be used as an additional methodological tool to support the achievement of the Sustainable Development Goals (SDGs) and provide evidence to support the promotion of the "freedom dividend" which would have far-reaching economic, social, cultural, and environmental benefits. Satellite remote sensing is likely to play an important role going forward for understanding these issues but should be augmented with ground-based data collection methods.
\end{abstract}

Keywords Fish-processing $\cdot$ Sundarbans $\cdot$ Bangladesh $\cdot$ Modern slavery $\cdot$ Sustainable Development Goals $\cdot$ Modern slavery-environmental degradation nexus

Electronic supplementary material The online version of this article (https://doi.org/10.1007/s40152-020-00199-7) contains supplementary material, which is available to authorized users.

Bethany Jackson

bethany.jackson1@nottingham.ac.uk

Doreen S. Boyd

doreen.boyd@nottingham.ac.uk

Christopher D. Ives

chris.ives@nottingham.ac.uk

Jessica L. Decker Sparks

jessica.sparks@nottingham.ac.uk

Giles M. Foody

giles.foody@nottingham.ac.uk

Stuart Marsh

stuart.marsh@nottingham.ac.uk
Kevin Bales

kevin.bales@nottingham.ac.uk

1 School of Geography, University of Nottingham, Sir Clive Granger Building, University Park, Nottingham NG7 2RD, UK

2 Rights Lab, University of Nottingham, Highfield House, University Park, Nottingham NG7 2RD, UK

3 Nottingham Geospatial Institute, University of Nottingham, Wollaton Road, Jubilee Campus, Nottingham NG8 1BB, UK

4 School of Politics and International Relations, Law and Social Sciences, University of Nottingham, University Park, Nottingham NG7 2RD, UK 


\section{Introduction}

Globally, there is growing recognition of the potential for satellite remote sensing data to expose environmentally damaging and illegal fishing activities, which in turn exacerbate environmental degradation (Al-Abdulrazzak and Pauly 2014; Belhabib et al. 2016; Oozeki et al. 2018; Kurekin et al. 2019; Young 2019). However, to date, this focus has mostly been placed on fishing activities at the marine extraction phase (Belhabib et al. 2016; Oozeki et al. 2018; Kurekin et al. 2019). There is a knowledge-gap with respect to land-based activities along the coastal fringe-including production through aquaculture and post-harvest fish-processing.

This paper documents prohibited fishing-based activities occurring in protected areas of the Sundarbans mangrove forest. Human activity varies across the forest and includes deforestation, village construction, the operation of fishprocessing camps, and aquaculture development. Some of this activity damages mangroves, thereby contravening conservation protections. Additionally, the use of modern slavery within processing camps has been reported (Jensen 2013; Bales 2016; McGoogan and Rashid 2016). To further elucidate the scale at which fish camps are present in the Sundarbans, we employ remotely sensed data to map their spatiotemporal patterns. Remote sensing can provide evidence to assess environmental activities (Boyd and Foody 2011), support conservation, and achieve sustainable protection of marine and terrestrial ecosystems (Anderson et al. 2017; Pettorelli et al. 2018). This has been applied to investigate mangrove ecosystems (Richards and Friess 2016; Lucas et al. 2017; Gandhi and Jones 2019) and is a suitable data source to understand the environmental impacts of the fisheries sector. In the coastal zone, remotely sensed measurements of environmental degradation have quantified mangrove deforestation rates (Hamilton and Casey 2016; Richards and Friess 2016), monitored erosion (Rahman et al. 2011; Payo et al. 2016), and assessed marine ecosystems, for example coral reefs (Hedley et al. 2016; Foo and Asner 2019). Remote sensing can also expose illegal environmental activities, such as hazardous waste and contamination (Lega et al. 2014), illegal logging (Popkin 2016), illegal oil spills (Sankaran 2019), and illegal mining (Suresh and Jain 2013). There is thus potential to combine difficult to collect ground-data on fisheries crimes with remote sensing data to triangulate knowledge of irregular activities, eventually leading to "sat-truthing" of that activity.

Applying remote sensing in this case is still a proxy measure at present (Landman et al. 2019), yet the unique capabilities of the technology can provide contextual insight into environmental degradation and identify sectors that may be vulnerable to cases of modern slavery. Satellite remote sensing data provide an expansive data source that can assess large, remote areas, over long periods of time, which can lead to insights that are unable to be collected on the ground with the same speed or scale, or with such replication. Insights gained as a result of satellite remote sensing can therefore enhance information gained on the ground - as is increasingly being applied to the issues contained in the Sustainable Development Goals (SDGs) (Anderson et al. 2017; Andries et al. 2018; Estoque 2020) - where the potential to provide vast amounts of data which help address SDG targets is unprecedented, when compared with other data collection methods for the reasons noted previously. These data may also assist in the identification areas in which we should direct focus for future environmental and social interventions. Thus, the power of analysing satellite data is linked to the wider understanding of the geographies in which human rights abuses occur, identifying areas for further research and providing details to support deeper analyses.

\section{Fish-processing and modern slavery}

Knowledge of land-based fishing activities is limited. For example, many rudimentary land-based fishing activities occur in remote coastal areas, primarily in developing countries; therefore, ground-data are often limited at these sites, meaning seasonality, scale of environmental degradation, and the length of operational activity at these sites are unknown. Access to ground-data can be hindered by the physical conditions of the mangroves, including shallow waters and extensive root networks. Moreover, many land-based activities are associated with other forms of fisheries crime. There have been cases of other illegal environmental activities within Bangladesh, including poaching of endangered species (Saif and MacMillan 2016), logging, collection of shrimp fry (Ahmed et al. 2019), and child labour and modern slavery in post-harvest fish-processing (Jensen 2013; Bales 2016) and shrimp production (EJF 2014; Verité 2016, 2017). Efforts have been made by the Food and Agriculture Organization (FAO) (2018a) to tackle child labour in the marine and aquaculture segments (e.g. in Thailand). As a result of this overwhelming focus on marine capture fisheries - for example in Thailand and New Zealand - exploitation in other areas, including fish-processing, has been overlooked. Some research connecting human rights and environmental damage (Sparks 2018; Tickler et al. 2018; Walk Free 2018) and illegal, unreported and unregulated (IUU) fishing (EJF 2019a, 2019b) has begun to appear, yet this has not engaged substantially with fish-processing.

Fish-processing is beginning to be investigated by environmental and antislavery organizations, with examples of labourers subjected to modern slavery being noted in the Thai processing sector (EJF 2018, 2019c, 2019d) reflecting wider issues in Thailand's fisheries. Jensen (2013) and Bales (2016) noted modern slavery in the dried fish-processing camps of Bangladesh, highlighting how indebtedness and 
labour exploitation are rooted in colonialism (Jalais 2004). These issues have been present across the Sundarbans (Jalais 2004) and similar abuses have been recognized in Myanmar's raft fisheries (Belton et al. 2019), where migrants in particular face risks. In Bangladesh, it is local communities who are at greater risk of poverty and are exposed to exploitative practices, being moved between rudimentary processing camps to more established manufacturing settings (Jensen 2013; Brown et al. 2019). In informal processing activities that operate outside the realm of regulatory measures and enforcement capabilities, some of the poorest and most vulnerable people are at high-risk of being subjected to modern slavery by perpetrators who recognize the need for family units to support themselves. Victims are often promised payment by recruiters if family members come and work for them, yet are exposed to poor working conditions and payments are often not made (Bales 2016). This exacerbates the effects of poverty, leaving families worse-off when they believed they were agreeing to legitimate forms of work.

Defined in this study as the exploitation of a person(s) through coercion, threat of, or actual violence (BellagioHarvard Guidelines 2012), modern slavery is an umbrella term that encompasses slavery, human trafficking, forced labour, and practices similar to slavery. Modern slavery in some cases also has a direct impact on the environment. The modern slavery-environmental degradation nexus (Bales 2016; Brown et al. 2019) has previously been noted in a number of sectors (e.g. brick-making, mining, agriculture, fishing). It explores the notion that modern slavery activities can lead to environmental degradation and that environmental factors can push vulnerable communities into situations of exploitation and modern slavery (Decker Sparks et al. under review). One example of the modern slavery-environment nexus are Cambodia's brick kilns: people have been forced from their agricultural land due to drought, where they become engaged in debt bondage within kilns that contribute significant concentrations of pollutants to the atmosphere (Brickell et al. 2018) thus continuing the pervasive cycle noted in the nexus. In terms of the fisheries sector, the feedback into the nexus can be more direct, such as the increased demand for fish and lack of labour regulation enforcement leading to issues of overfishing and modern slavery on fishing vessels (Sparks 2018). These examples suggest that the nexus operates as part of a wider sustained social-ecological system (SES), in which modern slavery is predicated by a number of social vulnerabilities that are inherently connected and effected by changes in both the environment and climate. This has led, and continues to lead to, a number of complex interactions that have previously been noted in relation to the brick-making industry (Brickell et al. 2018), but are similarly noted in Bangladesh's fish-processing camps. Understanding these processes is necessary if collaborative governance between conservation, antislavery, and governmental organizations is to occur. Thus enabling a variety of environmental issues, which occur as a result of human activities, to be addressed (Bodin 2017).

The nexus in fish-processing therefore arises from two factors - push and pull. "Push" factors are linked to economic pressures, such as poverty, the promises of improved livelihoods, and the exploitation of local communities by criminal organizations take advantage of the need to utilize the forest services of the Sundarbans Reserve Forest (SRF) (Kibria et al. 2018) - these factors and the system of labour exploitation and modern slavery are noted in Fig. 1. People are also "pulled" into the sector as a result of high demand for fish from the domestic and international markets, which is viewed by local people as an opportunity to support their livelihoods (Bales 2016; Hernandez et al. 2018; Dhar et al. 2020). Understanding the links between modern slavery drivers and how they may be linked to environmental degradation have been explored in multiple sectors by Decker Sparks et al. (under review). The presence of exploitative conditions in the fish camps can lead to the presence of environmentally degrading activities, some of which directly affect the forest, such as mangrove removal and loss of sequestration, as well as habitat degradation and biodiversity loss (Fig. 1); but also more extractive issues which have a greater impact on those who rely on the Sundarbans for their livelihoods (e.g. the extraction of fish stocks). These environmental impacts create vulnerabilities which mean people are at further risk of being placed on a path to exploitation in the camps. Children, boys in particular, are often those who are exploited in the Bangladesh fish camps (Jensen 2013), whereas in wider land-based fishing activities, the work of women and children (both boys and girls) is neglected (see Jensen 2013; EJF 2013, 2014). Therefore, remote sensing could assist in redressing this gender and age bias, and under-investigation of land-based activities, by elucidating high-risk areas.

Small-scale aquaculture development has been seen as an alternative livelihood approach to support rural development (Garcia et al. 2018; FAO 2018b) where there are risks of fish stock declines associated with overfishing and climate change (FAO 2016). However, evidence suggests that aquaculture itself could also be related to stock collapses in Asia through the catch of "trash feed" in order to supply feed for aquaculture farms (Garcia et al. 2018). As fisheries continue to face pressures, the vulnerability of small-scale aquaculture producers and subsistence fishers is likely to increase (FAO 2016), raising poverty levels, which may lead to further marginalization and vulnerability of people (Islam and Chuenpagdee 2013; Galappaththi and Nayak 2017; Bavinck 2018). Furthermore, climate change-related sea-level rise creates additional risk, damaging homes and livelihoods; thus, people requiring work may become trapped in forced criminal activity (such as illegal logging) or they may migrate leading to increased vulnerability to trafficking (IOM 2016; Molinari 2017). Climate change has also been associated with the 


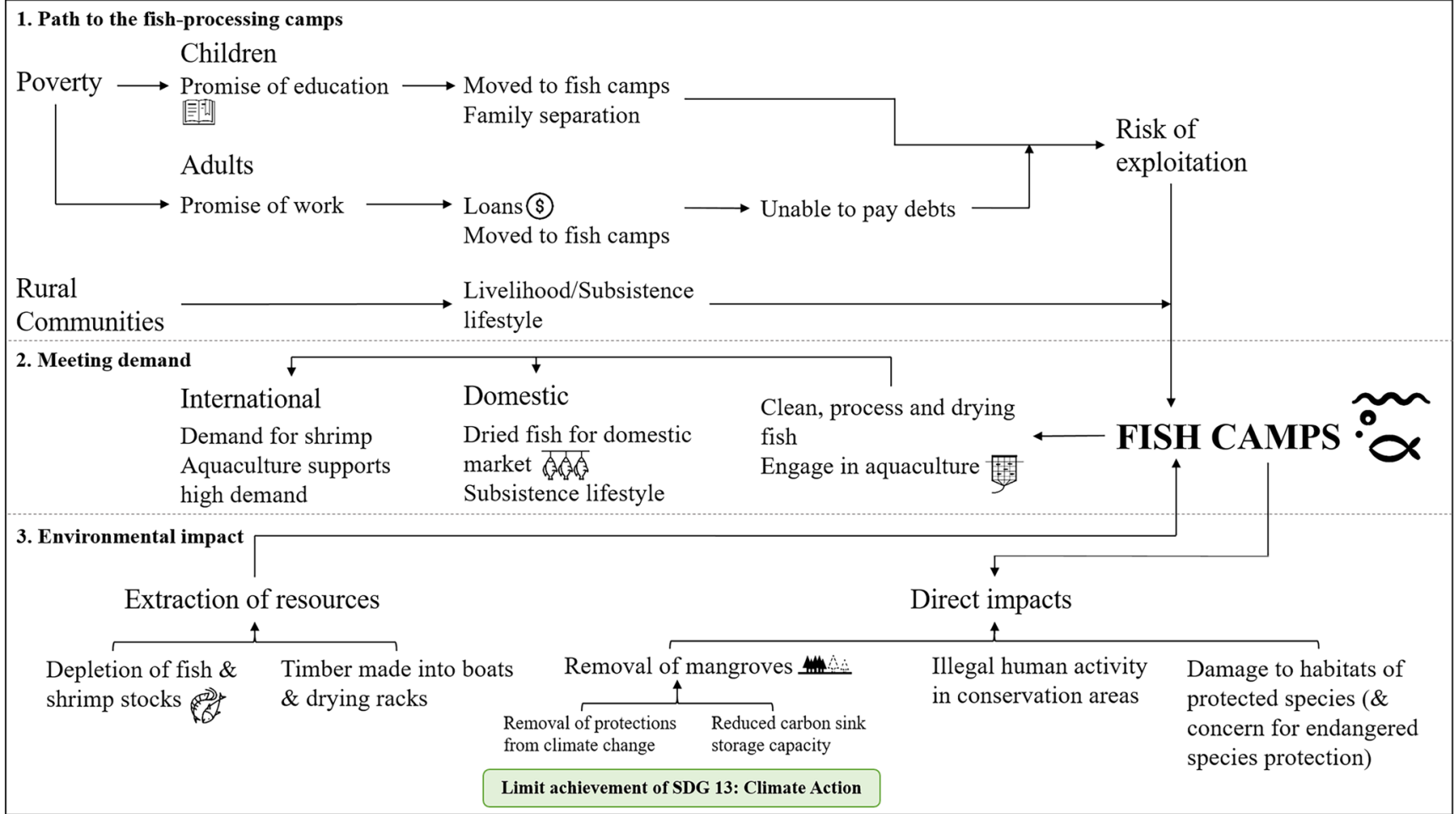

Fig. 1 Demonstrating the relationship between modern slavery and the natural mangrove ecosystem in relation to fish-processing camps, and why it is important to combat modern slavery due to the negative impacts which can be exerted on the environment as part of the nexus. This explores the path to labour exploitation and modern slavery, the drivers leading to modern slavery, and the environmental impacts of these phases. Information from a number of sources was used to develop the relationships which have been noted here; details associated with the path to fish-processing were obtained from Jensen (2013), Bales (2016), and

movement of people into illegal livelihood activities (Ahmed et al. 2019).

Modern slavery enables illegal environmental damage, in turn leading to increased vulnerability. Subsequently, ending modern slavery and the sustainability of fisheries are both included in the United Nations' (2016) SDGs. The interconnection between these issues implies that modern slavery is likely to contribute to environmental degradation in the Sundarbans and that associated risks to social vulnerability are unlikely to abate in the future. These risks warrant further investigation, particularly in under-represented land-based fishing activities. Addressing these concerns should allow greater understanding of the emerging modern slaveryenvironmental degradation nexus noted by Bales (2016) and Brown et al. (2019) which has since been expanded upon (Decker Sparks et al. under review).

To meet targets contained within SDG 8.7 (eradication of modern slavery), the drivers of labour exploitation and modern slavery and the locations in which they occur need to be understood. Remote sensing can be a tool to assess the nature of the links between modern slavery and the environment in
Brown et al. (2019); demand was noted by sources, such as Bales (2016), Hernandez et al. (2018), and Dhar et al. (2020); finally, the environmental impact of these camps is identified in the results of this paper, but also Bales (2016). These links are simplified and are likely to be impacted by further issues; however, these connections are the dominant paths noted in key literature related to land-based fishing activities. The pathway is based upon Brickell et al.'s (2018: 16-17) exploration of the pathway to labour exploitation and modern slavery within the Cambodian brick industry

the fisheries sector. Monitoring progress of the SDGs requires remotely sensed data (Anderson et al. 2017; Andries et al. 2018; Masó et al. 2019; Kavvada et al. 2020). Applying these data to assess often neglected land-based fishing activities enables further understanding of the impacts on SDG 14 ("Life below Water") and 15 ("Life on Land") in the coastal fringe. The presence of processing activities in these localities can lead to erosion and reduced sedimentation, deforestation, prohibited coastal development, and run-off affecting the delta, mangrove forest, and ocean. By using satellite remote sensing data, the evolution of land-based fishing activities in the SRF can reveal how fish-processing camps contribute to coastal damage, as has been evidenced in the marine environment (see Belhabib et al. 2019). This aligns with calls for increased use of remote sensing to assess the environmental impacts of modern slavery-supported activities (Jackson et al. 2018; Jackson 2019).

The Bangladesh Sundarbans Reserve Forest (SRF) is used as a case study to highlight the utility of remote sensing to fill data-gaps and demonstrate the role satellite remote sensing (also known as Earth Observation (EO)) data can play in 
identifying these camps. This knowledge can support further research by the following: (1) addressing the extent of human activity in the Sundarbans, including fish-processing camps; (2) determining the trends in camp operations over time; and (3) assessing the environmental impact of the fish-processing sites via the lens of the slavery-environment nexus using remotely sensed data. Our aim is to advance the understanding of the nexus and provides a clearer picture of the threats to people and ecosystems within the SRF. In doing so, we will consider how satellites may be used to help combat the modern slavery-environment nexus.

\section{Study area}

The Bangladesh SRF is part of the largest continuous mangrove forest in South Asia, covering a $6017 \mathrm{~km}^{2}$ area of land (Rahman et al. 2015). Ramsar and UNESCO World Heritage sites were established in 1992 and 1997, respectively. The "reserved forest" status allows for the continued extraction of resources in some locations. Three zones permit no human activity: Sundarbans West, South, and East (Ramsar 2003) (see Fig. 2). The mangroves support the livelihoods of those living in, and around, the forest due to the abundance of ecosystem services (Table S1). Local rural populations are the primary beneficiaries; many use traditional fishing practices, foraging and trapping, farming, and aquaculture to support subsistence lifestyles.

Fish-processing camps are present in the reserve, with some located in villages. They consist of mangrove-cleared areas with structures for landing, cleaning, and drying fish. The dominant market for processed fish is domestic. There have been reports of hazardous working conditions and exploitative practices in the camps (Jalais 2004; Jensen 2013; Bales 2016). Additional revenues can be gained through the operation of aquaculture ponds, farming shrimp, and mud crabs (Ahmed et al. 2017; Rahman et al. 2017). Drivers of labour exploitation and modern slavery in the SRF include the promise of work to support subsistence for those in the remote villages and of education (Fig. 1), as well as associated environmental drivers, such as climate change and unsustainable fish stocks.

\section{Methods}

Remote sensing data were chosen as they have unique capabilities to monitor the Earth providing vast quantities of spatial

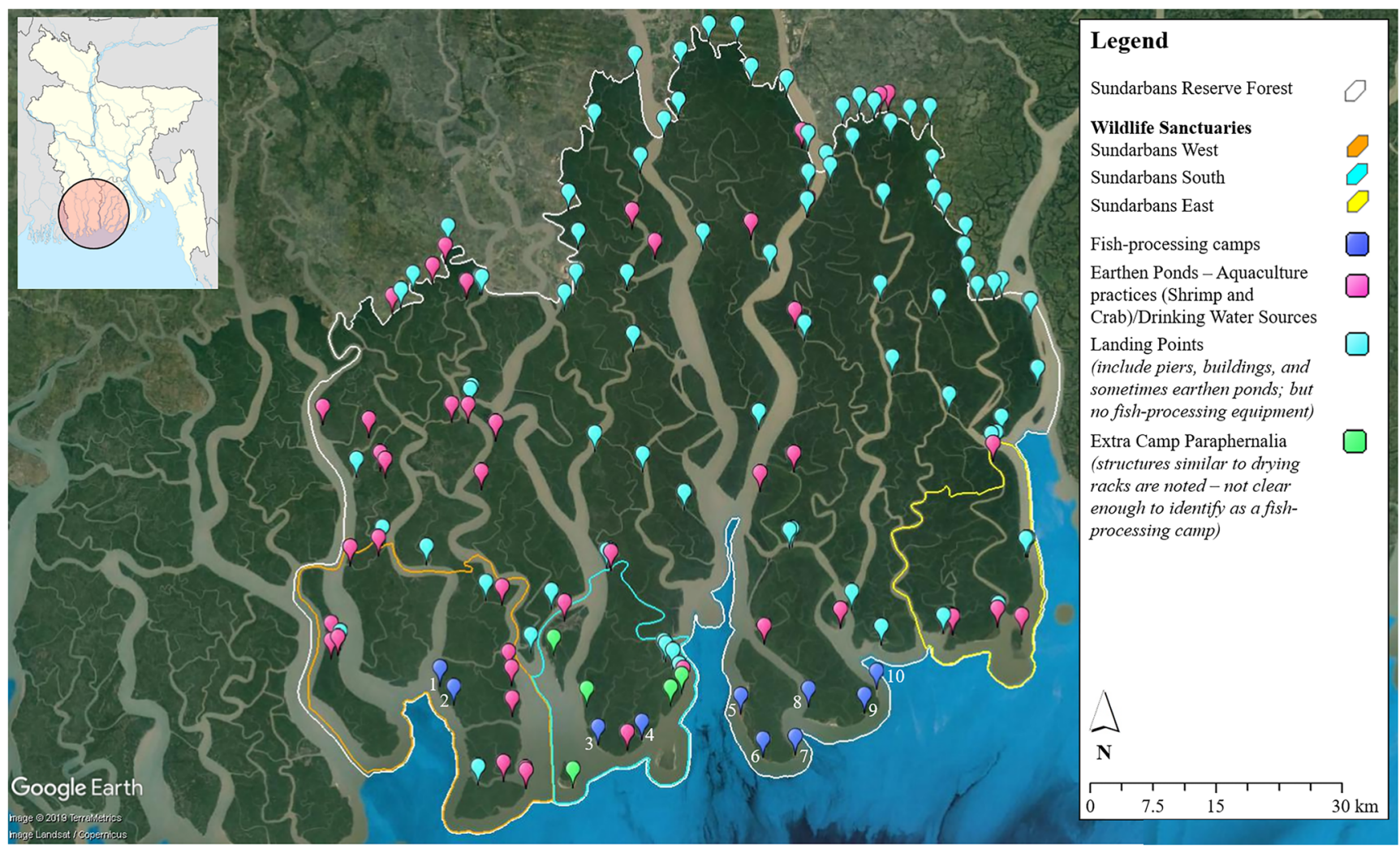

Fig. 2 Map of human activity evident within the Sundarbans Reserve Forest, Bangladesh. This includes 10 fish-processing camps to the South of the reserve (numbered). The three protected wildlife sanctuaries are also visible (Ramsar 2003), and their extent has been shown within the SRF boundary. Map data from Google: Landsat/Copernicus (2019) 
data at a range of temporal scales. The satellite EO data used were acquired by passive sensors which record an image of the electromagnetic radiation (sunlight) reflected from the Earth's surface that can be analysed to provide information about the region imaged (Aplin 2010). These underlying reflectance measurements enable analysis of the natural environment which can provide ecological assessments and help determine the effects of changing ecological systems. The historical collection of these data, in order to assess trends over time, makes remote sensing a valuable data source when assessing the SRF.

Several satellite EO data types were integrated to provide an assessment of the environmental implications of fishprocessing in the SRF. Data for the region were available on Google Earth Pro (GE Pro) (provided by DigitalGlobeWorldView; and CNES/Airbus-SPOT and Pléiades 1A/ 1B). A systematic visual search of the data available was undertaken from 2000 to 2018. Evidence of human activity was documented, including processing camps, boats, villages, and earthen ponds (Fig. 2). These ponds can be used for both aquaculture (Ahmed et al. 2017; Rahman et al. 2017) and drinking water purposes (where filtering techniques, such as those suggested by Øhlenschlæger et al. (2016), may be adapted to provide drinkable water from saltwater sources in the SRF). These features were identified by an image interpreter following a sampling protocol similar to that used by Boyd et al. (2018). Human-made features (both on land and bridging the water, e.g. buildings, earthen ponds, and jetties), areas where mangroves had been cleared in structured areas (e.g. rectangular clearings), and finally evidence of transport infrastructure, such as boats and shipping lanes, were all recorded. Noting the extent of all human activity is important for future conservation and management. Areas of mangrove loss and erosion located at the camp sites were calculated using measurement tools available in the software by measuring the total area of the camps, and the change in geographic area across the years where data were available. Moreover, using Bomer et al.'s (2020) study which measured the volume of carbon sequestered by the mangroves in the Sundarbans, an estimation of the sequestration capability lost in the SRF was calculated putting the environmental impact of these camps into context.

High-temporal resolution data from Planet Labs-which specializes in the development, launch, and operation of a high spatial-resolution "CubeSat" constellation known as Doves which hold the PlanetScope sensors (these have a $3 \mathrm{~m}$ spatial resolution, referring to the pixel area measured in the region of interest) (Hand 2015) - were used to understand the seasonal trends of the camps (including when the peak operating periods occur, and the times when vegetation has an opportunity to recover). Data were accessed via a partnership with the University of Nottingham. The three-month PlanetScope mosaic data for the year 2018 were downloaded for the Sundarbans. These data were used to determine the annual variations in camp operation. Moreover, longer-term Landsat data were used to provide an estimated formation date for each camp. Both $30 \mathrm{~m}$ spatial resolution (optical data, where there are separate red, green, blue, and near-infrared bands) and $15 \mathrm{~m}$ panchromatic data (this band is a single channel that combines the measurements from the red, green, and blue bands) were used to determine when the camps first appeared in the SRF. Data from the peak processing period (November-December) were downloaded and analysed. Data from 1999 to 2018 were downloaded for each year during these months. The locations of the camps as identified during the systematic visual search and the information noted by Jensen (2013) and Bales (2016) informed the spectral sampling of the Landsat data to estimate the age of the camps. These data span two Landsat sensors-Landsat 7 Enhanced Thematic Mapper (ETM+) and Landsat 8 Operational Land Imager (OLI); data were analysed spectrally, using reflectance (red, green, blue, and NIR; and the panchromatic band), to estimate camp age in ERDAS Imagine 2018. Sample points for analysis were taken from the camps, and the surrounding mangroves and water (for spectral comparison). Any differences in the spectral reflectance graphs were noted, the earliest year in which there were spectral differences at the camp locations were recorded as the estimated year of formation. These findings were assessed against GE Pro data to support the estimated year of formation assertion. A trade-off was made between the spatial resolution and timeseries to analyse the $15 \mathrm{~m}$ panchromatic band.

\section{Results}

Ten land-based fish-processing camps were identified in the SRF from 2000 to 2018 (Fig. 2), and their precise location was noted, to our knowledge, for the first time. Their size and occupation period varied (Table 1); changes in the mangrove environment and increased enforcement of conservation rules meant camps have been removed or responded by reducing in size. Meanwhile, some variations were a result of limited data coverage on GE Pro which should be addressed in future work by attaining funding to utilize high spatial-resolution data to fill the data gaps. All camps were found on the southern coast; some are likely to be obscured from ground view along smaller channels but are visible in satellite EO data. A number of camps were identified near the Indian border (camps 1-4); they were smaller and more secluded than the eastern sites (camps 5-10). These camps were briefly present, located within the conservation areas (Sundarbans West and South) (Ramsar 2003), and are likely to have been removed because of the breach in environmental law. The camps in the east are larger, typically containing hundreds of drying racks. Site 5 is the largest camp and is connected to the village of Alorkol on 
Table 1 Area of mangrove forest (ha) that the fish-processing camps covered across the SRF as measure in the high-resolution data available on Google Earth Pro (Provided by DigitalGlobe, Maxar Technologies, and CNES/Airbus), and the estimated volume of carbon which is no longer sequestered as a result of the removal of these mangroves for the camps - based on the volume of $240 \mathrm{~g} / \mathrm{m}^{2} /$ year by Bomer et al. (2020). Not all years are available (no data marked -) due to irregular updates to the platform, and some camps only have partial coverage (marked *)

\begin{tabular}{|c|c|c|c|c|c|c|c|}
\hline \multirow[t]{2}{*}{ Fish-processing site } & \multicolumn{7}{|c|}{ Year imagery available (Google Earth Pro) } \\
\hline & 2002 & 2006 & 2010 & 2011 & 2013 & 2014 & 2016 \\
\hline 1 & - & - & - & - & 0.66 & 0.61 & 0.62 \\
\hline 2 & - & - & - & - & 1.04 & 1.02 & 0.75 \\
\hline 3 & - & - & - & - & - & 0.42 & 0.36 \\
\hline 4 & - & - & - & - & 0.02 & 0.17 & 0.13 \\
\hline 5 & - & 139.98 & - & 110.91 & $97.92 *$ & 106.61 & $80.34 *$ \\
\hline 6 & 26.35 & $24.83 *$ & 25.06 & 24.51 & - & 19.71 & $9.56^{*}$ \\
\hline 7 & 29.40 & 54.25 & 40.80 & 36.39 & 29.64 & 28.21 & 23.00 \\
\hline 8 & - & 1.99 & - & 1.26 & 1.59 & 1.96 & 1.81 \\
\hline 9 & - & $1.52 *$ & - & 8.26 & 9.44 & 9.41 & 8.16 \\
\hline 10 & - & 17.99 & - & 17.17 & 18.85 & 17.46 & 15.59 \\
\hline $\begin{array}{l}\text { Total area affected by fish } \\
\text { camps ha per year }\end{array}$ & 55.75 & 240.56 & 65.86 & 198.49 & 159.17 & 185.59 & 140.32 \\
\hline $\begin{array}{l}\text { Estimated volume carbon sequestration } \\
\text { lost million } \mathrm{g} / \mathrm{m}^{2} / \text { year }\end{array}$ & 133.80 & 4811.20 & 13.17 & 476.38 & 382.01 & 445.42 & 336.77 \\
\hline
\end{tabular}

the island of Dublar Char. The overall area impacted by the camps fluctuates between 55.75 and 140.32 ha from 2002 to 2018 (Table 1), leading to an estimated sequestration loss of 336.77 million $\mathrm{C} \mathrm{g} / \mathrm{m}^{2} /$ year in 2016 . Whilst overall carbon sequestration is reduced (Table 1), the effect on the overall sequestration ability of the SRF is relatively small, between a minimum and maximum of $0.0009 \%$ (in 2010) and $0.33 \%$ (in 2006), respectively. Yet, this is a loss which limits the benefits of climate change mitigation, affecting the achievement of SDG 13 "Climate Action."

Earthen ponds (pools of impounded water along the river channels) (Hossain et al. 2013) were the most common human-made feature after the drying racks; they were present at five camps, predominantly in the east of the SRF. Overall, 81 landing sites or small settlements were identified from 2000 to 2018; these included villages, some of which had ponds-all found to the north of the SRF (Fig. 2). Moreover, 187 independent earthen pond structures were recorded (2000-2018). One such pond formed before the development of site 3 (to the north of the camp), and evidence of further pond development for aquaculture, or drinking water, is visible at site 9 during the 2016-2017 fish-processing season (Fig. 3).

Both sites 6 and 7 reduced in size and moved inland approximately $315 \mathrm{~m}$ (2002-2016) and $200 \mathrm{~m}$ (2006-2016) respectively, as erosion occurred; this was visible in the GE Pro data and measured using the in-software features. Erosion at other sites was limited compared with those seen at sites 6 and 7. The formation of a second earthen pond at site 9 may be explained by the partial collapse of the original structure; fluctuations in sedimentation upstream may affect the stability of the camps. Predicted destabilization of the delta corresponds to locations where mangrove removal has occurred for camp development (Rahman et al. 2011; Payo et al. 2016). Any continued erosion as a result of these camps could lead to the movement of the camps inland, thus contributing to further mangrove removal and loss of carbon sequestration capability. This destabilization directly impacts the achievement of SDG 6.6 which seeks to protect wetland environments.

Seasonal changes to the camps - including the removal of drying racks in the spring and summer months, and the reestablishment of the racks in the autumn and winter months when productivity is high — were visible in Planet's "3-month mosaic" data (Fig. 4), most notably at site 5. The village of Alorkol found adjacent to this site is the only feature remaining once the camp has been dismantled following the processing season. Partial vegetation recovery occurred between April and September 2018. The camps were fully operational during the post-monsoon winter months when fishing conditions are improved (Kay et al. 2018) and were visible in the high-temporal Planet imagery. Supply of fish to the camps is often conducted using small boats predominantly used for small-scale fishing (Fig. 5).

Camp age could not be confidently determined; however, sites $5-7,9$, and 10 appear to have been present in the earliest data from 1999. Moreover, the formation of sites 1-4 was identified in the Landsat 8 OLI data and corroborated by GE Pro (Table 2). Further investigation of camp age could be 

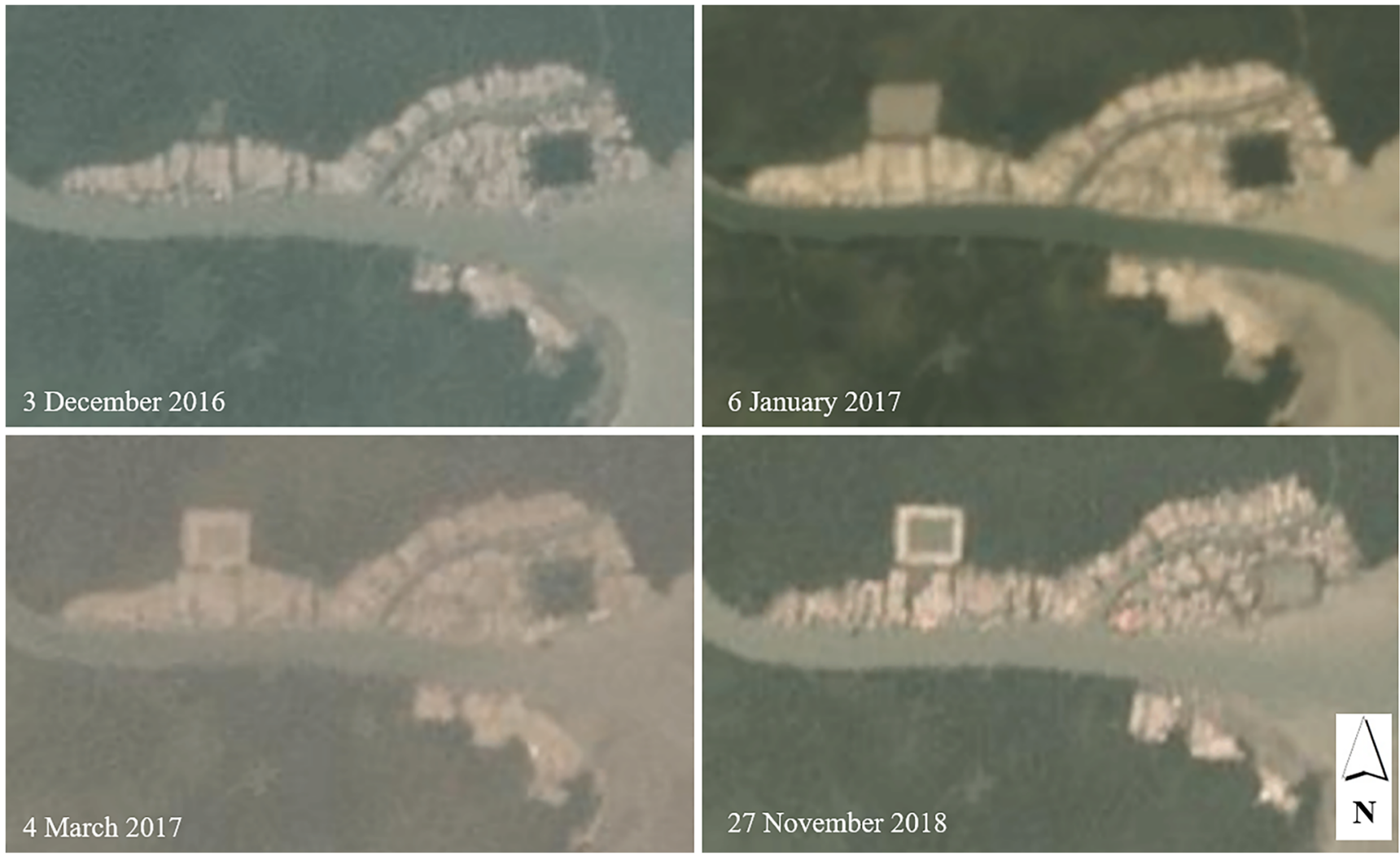

Fig. 3 Formation of the second shrimp pond at Site 9 (top-left of the image) in the Planet imagery 2016-2017 season. Imagery courtesy of Planet Labs (Planet Team 2018)

achieved by applying a similar algorithm to the fish camps as has previously been undertaken in the brick-making sector (see Li et al. 2019).

\section{Discussion}

Using remote sensing, this investigation has demonstrated the scale of environmental damage and seasonal trends in Bangladesh's fish-processing camps; camps where workers are subjected to modern slavery. Camp operation fluctuates seasonally (Fig. 4) to reflect the productivity of the water and the availability of fish (which increases from August, peaking between December and February) (Kay et al. 2018; Hossain et al. 2020). Evidence of modern slavery activity shifting to proximal warehouses and ports has been noted previously (Jensen 2013; Brown et al. 2019) as an adaptive response to changing environmental conditions, conditions that in some cases may result in increased vulnerability to modern slavery (Fig. 1). In response to these changes in the marine environment, evidence of aquaculture growth is evident. More than 180 earthen ponds (some involved in aquaculture) were identified across the SRF, with several located alongside the camps suggesting a shift in current activities. In turn, future land-based aquaculture could become the dominant environmentally degrading activity in the Sundarbans, with continued risk of labour exploitation and modern slavery for vulnerable populations reliant on fish products. These activities will also contribute to increased destabilization of the coastal fringe through erosion and reduced sedimentation (see Fig. 3); continued degradation of the delta, and increased vulnerability (Fig. 1) for those who rely on the mangroves.

Holistically addressing the nexus requires environmental change data; remote sensing provides the ability to understand these trends over large spatial extents. Open-access satellite sensors can capture data globally every five days (e.g. the European Space Agency's Sentinel-2 satellites; Drusch et al. 2012), whereas commercial providers, such as Planet, have rapidly developing daily monitoring capabilities (Hand 2015; Planet Team 2019). Almost 50 years of data can be accessed for archival analysis, and the number of planned missions are growing. Historical data provides the opportunity to understand previous (and future) environmental change dynamics in the mangrove system (see Heumann 2011; Giri 2016; Pham et al. 2019). These investigations could provide evidence to track human activities, such as modern slavery and its environmental effects. In areas where ground-data are not historically available, satellite EO data can fill these gaps - this is vital as ground-based research cannot be retroactively conducted, whereas geospatial analysis can.

In terms of addressing links between fish-processing and modern slavery as part of the nexus, the scale and identification of the camps have added to the understanding of overall 

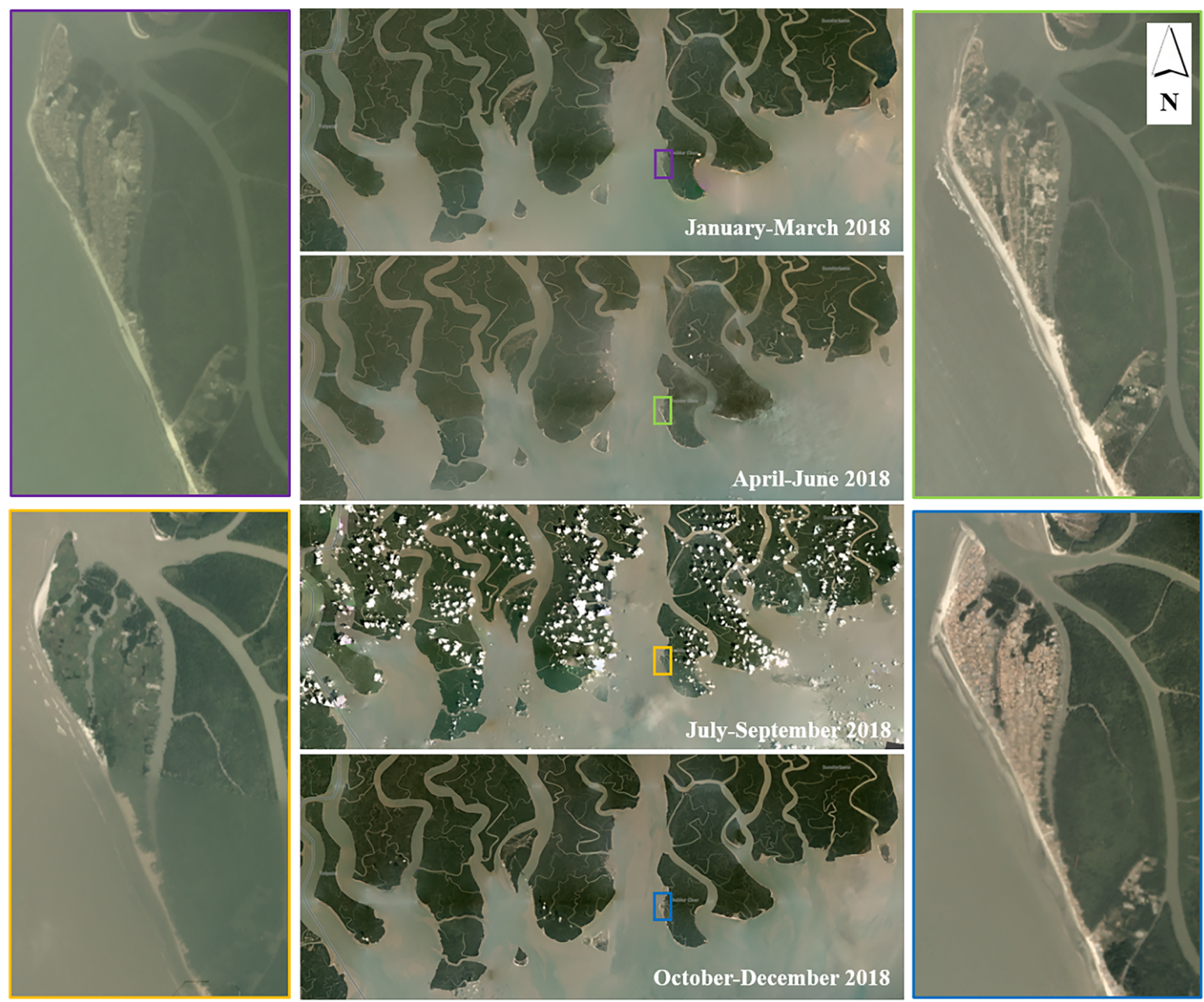

Fig. 4 The seasonal variation of the fish-processing camps in SRF seen in the "3-month mosaics" from Planet Labs (images courtesy of Planet Labs-Planet Team 2018). Surrounded by close shots of site 5 at the village of Alorkol where the variation is clear-colours of the images denote the season they were captured, visible in the wider SRF view human-environment damage in the mangroves (see Lynch et al. 2013; Chaussard and Kerosky 2016). The findings noted in this study provide quantitative data to support theorized connections between environmental change and modern slavery proposed in previous publications. For example, the notion of habitat loss explored by Bales (2016) has been measured by the scale and fluctuation of the camps over time (Table 1). The loss of mangroves is linked to additional ecosystem effects, including the continued risk of endangered species and lost carbon sequestration potential. Furthermore, Jensen (2013) references the risk of hard environmental conditions to which labourers subjected to modern slavery are exposed, including the risk of climate change and its impact upon rising sea-levels and cyclones. These risks noted by Jensen (2013), and reiterated by Brown et al. (2019), have also been identified with reference to the inter-relation between modern slavery and SDG 13 (Decker Sparks et al. under review). Whilst remote sensing may not definitively identify modern slavery activities, and triangulation with other sources are also necessary, these data can provide knowledge of environmental change over time at the camps across the Sundarbans.

The remoteness of fish-processing activities within protected areas increases risk of modern slavery (Bales 2016). This brings conservation management and governance to the fore of the social-ecological risks previously observed in the camps. Four camps were located in the Sundarbans West and South sites. These camps were short-lived and were swiftly removed as they were located in a protected area, and thus illegal. It appears that conservation management and governance within the Sundarbans is reactive, and respond, in cases where environmental crimes are actively occurring, but in 


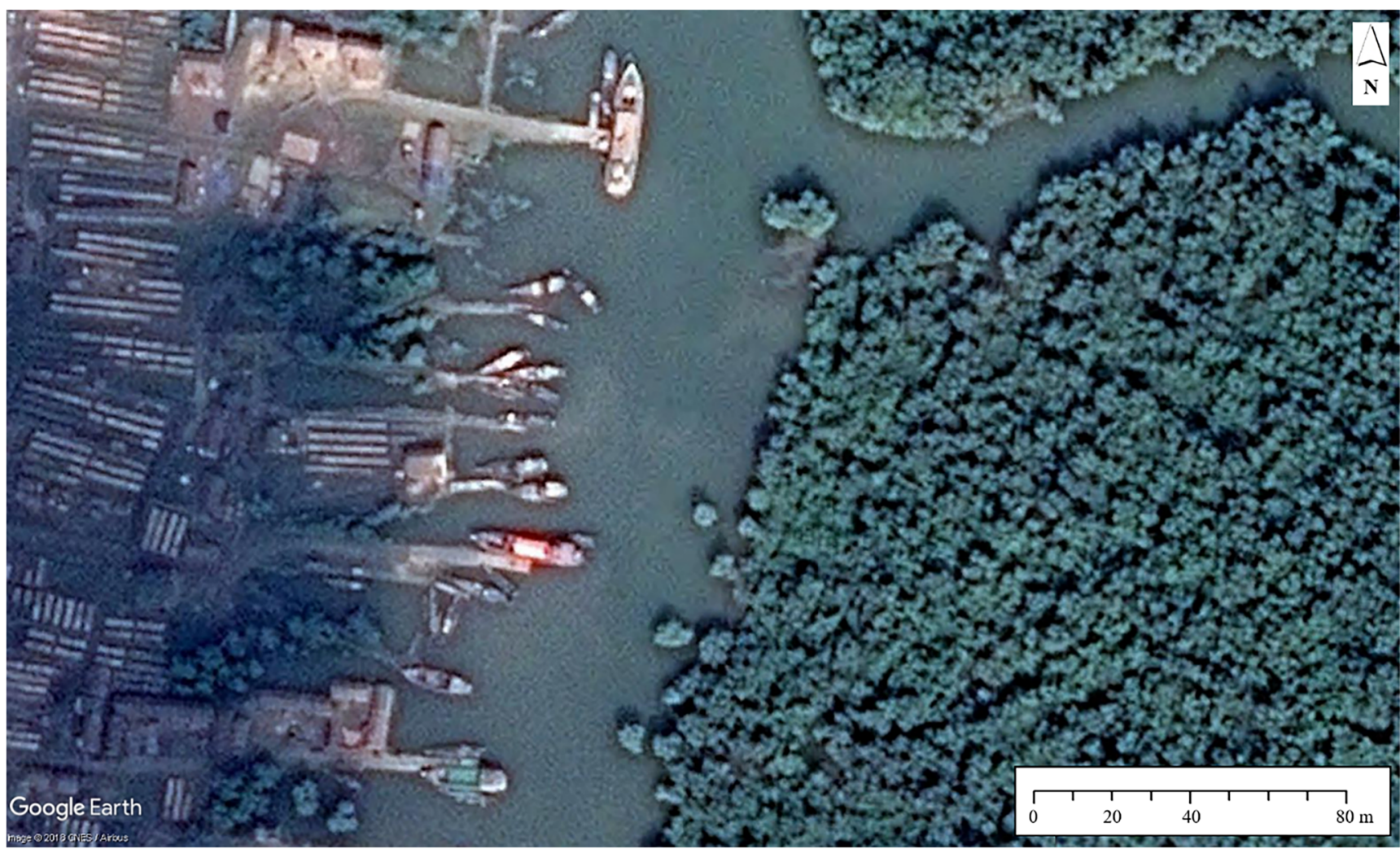

Fig. 5 Example of the fishing boats which were identified in the Sundarbans, available to view on the Google Earth Pro geobrowser, with imagery provided by Google: CNES/Airbus, captured 29.11.2016

areas where camps are legally allowed to operate (the SRF is a "reserve" forest, meaning there are areas in which people are allowed to access and extract resources), the repeated reports of labour exploitation and modern slavery have not been met with the same response. Joint efforts to address social-ecological issues should incorporate the complexities of environmental crimes, and tackle labour exploitation and modern slavery at the same legislative level. Intersections between governance (legal and governmental) actors, as well as conservation and antislavery organizations are something which have previously been proposed in other sectors, such as forestry, and could be applied in the context of the mangroves (Jackson et al. 2020; Jackson and Decker Sparks 2020).

Other nations have addressed the social vulnerabilities of modern slavery, some of these lessons may be applied to our understanding of land-based fish-processing in Bangladesh. One such programme was the International Labour Organization's "Ship to Shore Rights" initiative (ILO 2018) that operated across the Thai fishing and seafood industry, and
Table 2 Landsat data identification dates from the panchromatic band (band 8 for both the ETM+ and OLI sensors). The earliest data in which the fishprocessing camps were visible were noted. The data were downloaded via the USGS Earth Explorer platform

\begin{tabular}{lllll}
\hline Fish-processing Site & $\begin{array}{l}\text { Year fish camp } \\
\text { first visible }\end{array}$ & Satellite platform & $\begin{array}{l}\text { Sensor } \\
\text { (with panchromatic band) }\end{array}$ & $\begin{array}{l}\text { Date of the } \\
\text { imagery assessed }\end{array}$ \\
\hline 1 & 2013 & Landsat 8 & OLI & 24.12 .2013 \\
2 & 2013 & Landsat 8 & OLI & 24.12 .2013 \\
3 & 2014 & Landsat 8 & OLI & 25.11 .2014 \\
4 & 2014 & Landsat 8 & OLI & 25.11 .2014 \\
5 & Before 1999 & Landsat 7 & ETM+ & 08.11 .1999 \\
6 & Before 1999 & Landsat 7 & ETM+ & 08.11 .1999 \\
7 & Before 1999 & Landsat 7 & ETM+ & 08.11 .1999 \\
8 & 2010 & Landsat 7 & ETM+ & 24.12 .2010 \\
9 & Before 1999 & Landsat 7 & ETM+ & 08.11 .1999 \\
10 & Before 1999 & Landsat 7 & ETM+ & 08.11 .1999
\end{tabular}


included objectives to support workers and "victims of labour abuses, including women and children" (ILO 2019). Moreover, remote sensing can assist in the future production of antislavery initiatives, as well as providing monitoring and evaluation for these schemes. In order to apply similar efforts in Bangladesh, approaches will need to be applied to the informal and formal parts of the fish-processing segment. The fish camps identified in this study are informal in their presence, meaning modern slavery and lack of regulation can thrive. However, further inland, there are more industrialized processing factories to which workers may be moved (Jensen 2013; Brown et al. 2019) during periods where it is not possible to operate the informal camps - for example, the monsoon and cyclone seasons. In the more formal settings of Bangladesh's fishing sector, schemes similar to the ILO's "Ship to Shore Rights" initiative may be successfully translated to provide worker protections. However, the informality of the whole Bangladesh fisheries sector-including fishprocessing camps - is a much larger proportion of the economy, employing more than 1 million people (over $80 \%$ of them male) (Maligalig et al. 2009), yet the fisheries sector only contributes a small amount to the overall GDP (4\% of GDP is produced through informal fishing practices in Bangladesh) (Maligalig et al. 2009). This is in contrast to other nations in the region, such as Thailand, where the sector is more formalized, there is international leverage as there is a vast amount of international trade (FAO 2019) and transnational migrants make up a large proportion of those who may be exploited in the sector (Chantavanich et al. 2016; Issara Institute and IJM 2017; ILO 2018). This is in stark contrast to the sector in Bangladesh where trade is predominantly domestic (Department of Fisheries Bangladesh 2018), and where local Bangladeshi communities have been documented in cases of exploitation within the fish camps (Jensen 2013; Bales 2016). Whilst the application of programmes, such as "Ship to Shore Rights" may be appropriate for cases of exploitation noted in the smaller formalized processing sector in Bangladesh (see Jensen 2013; Brown et al. 2019), they may not be applicable for those in more informal, and remote locations which rely on the water for fish, and the mangrove forest for processing space. This is something that may change in the future as Bangladesh pushes towards a "Blue Economy" model (Hasan et al. 2018), but is unlikely to be successful in the current informal economy. As a result of the informal fisheries sector, a case can be made for a more integrated method of training provision for conservationists who are likely to come into primary contact with those who may be subjected to modern slavery, as proposed in other forestry sectors where modern slavery and environmental degradation intersect (Jackson and Decker Sparks 2020).

Remote sensing is touted as a methodology that should be incorporated to further understand the impacts of modern slavery affected sectors (Drejer and Bales 2018; Landman 2018;
Jackson et al. 2018; Landman et al. 2019; Jackson 2019), and long-term integration aims to provide insights into the modern slavery-environmental degradation nexus that may assist environmental governance and antislavery action. There are several specific operational benefits of applying remote sensing to investigate the SRF. First, remote sensing is scalable; this is the dominant benefit of applying these data to investigate post-harvest fish-processing, marine capture fisheries, and aquaculture activities (the latter is being analysed using Sentinel-1 Synthetic-Aperture Radar (SAR): see Ottinger et al. 2018; Prasad et al. 2019) in locations where modern slavery occurrence is high-risk, or has been documented. Second, satellite EO is a relatively inexpensive and costeffective data collection method (Woellert et al. 2011; Foody et al. 2019). Finally, Verité (2016) note that operations, such as shrimp farming, often occur in dangerous and inaccessible areas; satellite sensors can provide these data in a safe manner. Including remotely sensed data would begin to readdress the neglect of land-based fishing activities, rebalancing our understanding of the social-ecological implications of these activities.

However, several limitations exist that are important to acknowledge. The primary limit is acknowledging that modern slavery per se cannot be identified using these technologiesrather, it is the sector which can be identified. Whilst this is a clear limitation of the application of remotely sensed data at present, the importance of being able to identify the fishprocessing camps provides information which can be used by environmental and antislavery organizations alike to support the call for better environmental governance in the Sundarbans, and better working conditions. Furthermore, satellite EO data can form part of the method to triangulate data around cases of modern slavery and environmental degradation. This integration should seek to combine secondary data sources, such as those by Jensen (2013) and Bales (2016), with remotely sensed satellite EO data, and primary ground-data collected at the same time-period that the satellite data are collected. Primary ground-truthed data may then also be collected on the social and environmental conditions of these camps, where additional identifiable features may be noted that cannot be measured by the remote sensing data. The collection of primary ground-data will be vital in research moving forward, as it is important for the grounding of research results interpreted from the satellite data. Such improvements can assist in the governance of the Sundarbans by providing detailed evidence of the socialecological impacts of fish-processing. Moreover, triangulation may eventually lead to the establishment of true "sat-truthing," as well as direct prediction and identification of locations where modern slavery is occurring, such as has been proposed by the UN (Landman et al. 2019).

There were additional limitations specific to this study, for example, data available on GE Pro were temporally sporadic and did not always provide coverage for the ten camps in the 
same scene, or timeframe. Only a snapshot of the SRF is provided: whilst this enables the characterization of trends in fishprocessing activities, it is not holistic. Planet does not have the same spatial detail as the commercial data on GE Pro. Additional trade-offs are found in the temporal availability; Planet has a limited data archive despite collecting data frequently. These data fill some gaps in the GE Pro archive, but they do not completely resolve the issue of sporadic data. Going forward these limitations should decline, but there is little that can be done regarding high spatial- and temporal-resolution data access for limited cost. Moreover, analysis of Landsat's $30 \mathrm{~m}$ data determined little-tono spectral difference between the camps and mangroves. Even with the $15 \mathrm{~m}$ panchromatic band, the estimated age of the camps was difficult to determine and may have formed before 1999, but this was not identified as panchromatic data were only available from 1999 (within the ETM+ sensor). Finally, striping in the ETM+ data following the Scan Line Corrector failure (SLC-off products) (USGS 2003) obscured some sites - affecting 2007, 2011, and 2012 data.

\section{Conclusion}

Land-based post-harvest fishing activities along the coastal fringe have largely been overlooked by antislavery organizations and the marine development community. As demonstrated here, remote sensing is an additional tool that can investigate the extent to which these activities operate over space and time. This study focused on fish camps in the Bangladesh Sundarbans and demonstrated the varied environmental effects of these operations in a semi-closed system. Camps were identified in areas where human activity is prohibited, and the area of deforestation and land lost through erosion was quantified. Furthermore, additional revenue streams are likely being produced through small-scale aquaculture ponds. These sites have previously documented cases of modern slavery in their workforce. To understand the connection between modern slavery and environmental degradation as part of the nexus (Brown et al. 2019; Decker Sparks et al. under review), the extent to which these camps affect the mangrove forests - both spatially and temporally - need to be quantified, so governance from both antislavery and conservation actors may play a role in addressing social-ecological issues. Remote sensing has provided this context, and the next phase should be assessing this connection by undertaking ground-data collection with relevant stakeholders.

To fully address the nexus and the SDGs, further ground-data are required; remote sensing should be applied going forward (Jackson et al. 2018) as part of a wider investigation approach (Landman et al. 2019; Jackson 2019; Scoles 2019). The benefits of ending modern slavery and protecting the environment are contained in the "freedom dividend" (Bales 2012) — where social prospects improve, economic benefits are achieved, and the environment is protected. It is imperative that the study of the fisheries sector expands to include land-based activities, particularly when striving to address modern slavery. By achieving this in the SRF and limiting criminal activities, the ecological integrity of the mangroves can be protected, and those who rely on the SRF can be supported. Further insight into the SES of the nexus between modern slavery and the environment can be gained using satellite EO data, ultimately providing a case for continued use of these data. Remote sensing provides an opportunity to expand our knowledge of environmental degradation, fishprocessing activities, and the impact of modern slavery, supporting multiple social and environmental SDGs.

Acknowledgements The authors would like to thank Planet Labs for their partnership with the Rights Lab, University of Nottingham, and Google Earth for making data openly accessible. This work was supported by the UK's Economic and Social Research Council (ESRC) [ES/ T501992/1].

Author contributions BJ conducted the analysis of the remote sensing data for the fish-processing camps in the Sundarbans under guidance from DB, GF and SM. The work used data collected by KB as the basis for the ground-truthing. Development of the manuscripts' narrative was assisted by CI and JS, with writing of the manuscript led by BJ. Supplementary materials and the connections between modern slavery and environmental vulnerability were produced, structured, and formed by BJ and CI. Finally, extensive comments were provided by all authors, in particular DB, CI and JS.

Funding This work was supported by the UK's Economic and Social Research Council (ESRC) [ES/T501992/1].

Data availability Data will be made available on the University of Nottingham's research data repository (https://rdmc.nottingham.ac.uk/).

\section{Compliance with ethical standards}

Conflicts of interest The authors declare that they have no conflict of interest.

Open Access This article is licensed under a Creative Commons Attribution 4.0 International License, which permits use, sharing, adaptation, distribution and reproduction in any medium or format, as long as you give appropriate credit to the original author(s) and the source, provide a link to the Creative Commons licence, and indicate if changes were made. The images or other third party material in this article are included in the article's Creative Commons licence, unless indicated otherwise in a credit line to the material. If material is not included in the article's Creative Commons licence and your intended use is not permitted by statutory regulation or exceeds the permitted use, you will need to obtain permission directly from the copyright holder. To view a copy of this licence, visit http://creativecommons.org/licenses/by/4.0/.

\section{References}

Ahmed, Nesar, William W.L. Cheung, Shirley Thompson, and Marion Glaser. 2017. Solutions to blue carbon emissions: shrimp cultivation, mangrove deforestation and climate change in coastal 
Bangladesh. Marine Policy 82: 68-75. https://doi.org/10.1016/j. marpol.2017.05.007.

Ahmed, Istiakh, Sonja Ayeb-Karlsson, Kees van der Geest, Saleemul Huq, and Joanne Catherine Jordan. 2019. Climate change, environmental stress and loss of livelihoods can push people towards illegal activities: a case study from coastal Bangladesh. Climate and Development 11 (10): 907-917. https://doi.org/10.1080/17565529. 2019.1586638.

Al-Abdulrazzak, Dalal, and Daniel Pauly. 2014. Managing fisheries from space: Google Earth improves estimates of distant fish catches. ICES Journal of Marine Science 71 (3): 450-454. https://doi.org/10.1093/ icesjms/fst178.

Anderson, Katherine, Barbara Ryan, William Sonntag, Argyro Kavvada, and Lawrence Friedl. 2017. Earth observation in service of the 2030 Agenda for Sustainable Development. Geo-Spatial Information Science 20 (2): 77-96. https://doi.org/10.1080/10095020.2017. 1333230.

Andries, Ana, Stephen Morse, Richard Murphy, Jim Lynch, Emma Woolliams, and John Fonweban. 2018. Translation of Earth observation data into sustainable development indicators: an analytical framework. Sustainable Development 27: 366-376. https://doi.org/ 10.1002/sd.1908.

Aplin, Paul. 2010. Using remotely sensed imagery. In Key methods in geography, ed. Nicholas Clifford, Shaun French, and Gill Valentine, 2nd ed., 299-314. London: Sage.

Bales, Kevin. 2012. Disposable people: new slavery in the global economy. 2nd ed. Berkeley CA: University of California Press.

Bales, Kevin. 2016. Blood and earth: modern slavery, ecocide and the secret to saving the world. New York NY: Spiegel \& Grau.

Bavinck, Maarten. 2018. Legal pluralism, governance, and the dynamics of seafood supply chains - explorations from South Asia. Maritime Studies 17 (3): 275-284. https://doi.org/10.1007/s40152-018-0118-4.

Belhabib, Dyhia, Pierre Campredon, Najih Lazar, U. Rashid Sumaila, Braham Cheikh Baye, Elimane Abou Kane, and Daniel Pauly. 2016. Best for pleasure, not for business: evaluating recreational marine fisheries in West Africa using unconventional sources of data. Palgrave Communications 2: 15050. https://doi.org/10.1057/ palcomms.2015.50.

Belhabib, Dyhia, William W.L. Cheung, David Kroodsma, Vicky W.Y. Lam, Philip J. Underwood, and John Virdin. 2019. Catching industrial fishing incursions into inshore waters of Africa from space. Fish and Fisheries 00: 1-14. https://doi.org/10.1111/faf.12436.

Bellagio-Harvard Guidelines. 2012. The Bellagio-Harvard guidelines on the legal parameters of slavery. https://glc.yale.edu/sites/default/ files/pdf/the_bellagio-_harvard_guidelines_on_the_legal_ parameters_of_slavery.pdf Accessed 12 February 2020.

Belton, Ben, Melissa Marschke, and Peter Vandergeest. 2019. Fisheries development, labour and working conditions on Myanmar's marine resource frontier. Journal of Rural Studies 69: 204-213. https://doi. org/10.1016/j.jrurstud.2019.05.007.

Bodin, Örjan. 2017. Collaborative environmental-governance: achieving collective action in social-ecological systems. Science 357 (6352): eaan1114. https://doi.org/10.1126/science.aan1114.

Bomer, Edwin J., Carol A. Wilson, and Tracy Elsey-Quirk. 2020. Process controls of the live root zone and carbon sequestration capacity of the Sundarbans Mangrove Forest, Bangladesh. Sci 2 (2): 35. https:// doi.org/10.3390/sci2020035.

Boyd, Doreen S., and Giles M. Foody. 2011. An overview of recent remote sensing and GIS based research in ecological informatics. Ecological Informatics 6 (1): 25-36. https://doi.org/10.1016/j. ecoinf.2010.07.007.

Boyd, Doreen S., Bethany Jackson, Jessica Wardlaw, Giles M. Foody, Stuart Marsh, and Kevin Bales. 2018. Slavery from space: demonstrating the role for satellite remote sensing to inform evidencebased action related to UN SDG number 8. ISPRS Journal of
Photogrammetry and Remote Sensing 142: 380-388. https://doi. org/10.1016/j.isprsjprs.2018.02.012.

Brickell, Katherine, Laurie Parsons, Nithya Natarajan, and Sopheak Chann. 2018. Blood bricks: untold stories of modern slavery and climate change from Cambodia. London: Royal Holloway University of London.

Brown, David, Doreen S. Boyd, Katherine Brickell, Christopher D. Ives, Nithya Natarajan, and Laurie Parsons. 2019. Modern slavery, environmental degradation and climate change: fisheries, field, forests and factories. ENE: Nature and Space 0 (0): 1-17. https://doi.org/ $10.1177 / 2514848619887156$.

Chantavanich, Supang, Samarn Laodumrongchai, and Christina Stringer. 2016. Under the shadow: forced labour among sea fishers in Thailand. Marine Policy 68: 1-7. https://doi.org/10.1016/j.marpol. 2015.12.015.

Chaussard, Estelle, and Sara Kerosky. 2016. Characterization of black sand mining activities and their environmental impacts in the Philippines using remote sensing. Remote Sensing 8 (2): 100. https://doi.org/10.3390/rs8020100.

Department of Fisheries Bangladesh. 2018. Yearbook of fisheries statistics of Bangladesh, 2017-18. Vol. 25. Dhaka: Fisheries Resources Survey System, Department of Fisheries, Ministry of Fisheries.

Dhar, Aurup Ratan, Md Taj Uddin, and Mrinal Kanti Roy. 2020. Assessment of organic shrimp farming sustainability from economic and environmental viewpoints in Bangladesh. Environmental Research 180: 108879. https://doi.org/10.1016/j.envres.2019. 108879.

Drejer, Catherine, and Kevin Bales. 2018. \#SlaveTech: a snapshot of slavery in a digital age. Oslo: Skaperkraft.

Drusch, M., U. Del Bello, S. Carlier, O. Colin, V. Frenandez, F. Gascon, B. Hoersch, C. Isola, P. Laberinti, P. Martimort, A. Meygret, F. Spoto, O. Sy, F. Marchese, and P. Bargellini. 2012. Sentinel-2: ESA's optical high-resolution mission for GMES operational services. Remote Sensing of Environment 120: 25-36. https://doi.org/ 10.1016/j.rse.2011.11.026.

Environmental Justice Foundation. 2013. The hidden cost: human rights abuses in Thailand's shrimp industry. London: EJF.

Environmental Justice Foundation. 2014. Impossibly cheap: abuse and injustice in Bangladesh's shrimp industry. London: EJF.

Environmental Justice Foundation. 2018. Out of the shadows: improving transparency in global fisheries to stop illegal, unreported and unregulated fishing. London: EJF.

Environmental Justice Foundation. 2019a. Blood and water: human rights abuse in the global seafood industry. London: EJF.

Environmental Justice Foundation. 2019b. Illegal fishing and child labour in Vietnam's fishing fleet. London: EJF.

Environmental Justice Foundation. 2019c. Thailand's road to reform: securing a sustainable, legal and ethical fishery. London: EJF.

Environmental Justice Foundation. 2019d. Thailand's progress in combatting IUU forced labour \& human trafficking. London: EJF.

Estoque, Ronald C. 2020. A review of the sustainability concept and the state of SDG monitoring using remote sensing. Remote Sensing 12 (11): 1770. https://doi.org/10.3390/rs12111770.

Foo, Shawna A., and Gregory P. Asner. 2019. Scaling up coral reef restoration using remote sensing technology. Frontiers in Marine Science 6: 79. https://doi.org/10.3389/fmars.2019.00079.

Food and Agriculture Organization. 2016. Brief on fisheries, aquaculture and climate change in the Intergovernmental Panel on Climate Change fifth assessment report (IPCC AR5). Rome: FAO.

Food and Agriculture Organization. 2018a. Eliminating child labour in fisheries and aquaculture - promoting decent work and sustainable fish value chains. Rome: FAO. http://www.fao.org/3/CA0177EN/ ca0177en.pdf Accessed 12 February 2020.

Food and Agriculture Organization. 2018b. The state of world fisheries and aquaculture 2018: meeting the sustainable development goals. 
Rome: FAO http://www.fao.org/3/i9540en/i9540en.pdf Accessed 12 February 2020.

Food and Agriculture Organization. 2019. Fishery and aquaculture country profiles: the kingdom of Thailand. http:/www.fao.org/fishery/ facp/THA/en Accessed 26 June 2020.

Foody, Giles M., Feng Ling, Doreen S. Boyd, Xiaodong Li, and Jessica Wardlaw. 2019. Earth observation and machine learning to meet sustainable development goal 8.7: mapping sites associated with slavery from space. Remote Sensing 11 (3): 266. https://doi.org/10. 3390/rs11030266.

Galappaththi, Eranga K., and Prateep K. Nayak. 2017. Two faces of shrimp aquaculture: commonising vs. decommonising effects of a wicked driver. Maritime Studies 16: 12. https://doi.org/10.1186/ s40152-017-0066-4.

Gandhi, Samir, and Trevor Gareth Jones. 2019. Identifying mangrove deforestation hotpots in South Asia, Southeast Asia and AsiaPacific. Remote Sensing 11 (6): 728. https://doi.org/10.3390/ rs11060728.

Garcia, S.M., Y. Ye, J. Rice, and A. Charles. 2018. Rebuilding of marine fisheries. Part 1: global review. FAO fisheries and aquaculture technical paper no. 630/1. Rome: FAO. http://www.fao.org/3/ca0161en/ CA0161EN.pdf accessed 12 February 2020.

Giri, Chandra. 2016. Observation and monitoring of mangrove forests using remote sensing: opportunities and challenges. Remote Sensing 8 (9): 783. https://doi.org/10.3390/rs8090783.

Hamilton, Stuart E., and Daniel Casey. 2016. Creation of a high spatiotemporal resolution global database of continuous mangrove forest cover for the 21st century (CGMFC-21). Global Ecology and Biogeography 25 (6): 729-738. https://doi.org/10.1111/geb.12449.

Hand, Eric. 2015. Startup liftoff. Science 348 (6231): 172-177. https:// doi.org/10.1126/science.348.6231.172.

Hasan, M. Monjur, B.M. Sajjad Hossain, M. Jobaer Alam, K.M. Azam Chowdhury, Ahmad Al Karim, and Nuruddin M. Khaled Chowdhury. 2018. The prospects of blue economy to promote Bangladesh into a middle-income country. Open Journal of Marine Science 8 (3): 355-369. https://doi.org/10.4236/ojms.2018. 83019.

Hedley, John D., Chris M. Roelfsema, Iliana Chollett, Alastair R. Harborne, Scott F. Heron, Scaría Weeks, William J. Skirving, Alan E. Strong, C. Mark Eakin, Tyler R.L. Christensen, Victor Ticzon, Sonia Bejarano, and Peter J. Mumby. 2016. Remote sensing of coral reefs for monitoring and management: a review. Remote Sensing 8 (2): 118. https://doi.org/10.3390/rs8020118.

Hernandez, Ricardo, Ben Belton, Thomas Reardon, Chaoran Hu, Xiaobo Zhang, and Akhter Ahmed. 2018. The "quiet revolution" in the aquaculture value chain in Bangladesh. Aquaculture 493: 456468. https://doi.org/10.1016/j.aquaculture.2017.06.006.

Heumann, Benjamin W. 2011. Satellite remote sensing of mangrove forests: recent advances and future opportunities. Progress in Physical Geography: Earth and Environment 35 (1): 87-108. https://doi.org/10.1177/0309133310385371.

Hossain, M.S., M.J. Uddin, and A.N.M. Fakhruddin. 2013. Impacts of shrimp farming on the coastal environment of Bangladesh and approach for management. Reviews in Environmental Science and Biotechnology 12 (3): 313-332. https://doi.org/10.1007/s11157013-9311-5.

Hossain, M. Shahadat, Subrata Sarker, S.M. Sharifuzzaman, and Sayedur Rahman Chowdhury. 2020. Primary productivity connects Hilsa fishery in the Bay of Bengal. Scientific Reports 10: 5659. https:// doi.org/10.1038/s41598-020-62616-5.

International Labour Organization. 2018. Ship to shore rights: baseline research findings on fishers and seafood workers in Thailand. Bangkok: ILO.

International Labour Organization. 2019. Ship to shore rights. ILO https://shiptoshorerights.org/ Accessed 16 December 2019.
International Organization for Migration. 2016. The climate changehuman trafficking nexus. Bangkok: IOM Regional Office for Asia and the Pacific.

Islam, Mohammad Mahmudul, and Ratana Chuenpagdee. 2013. Negotiating risk and poverty in mangrove fishing communities of the Bangladesh Sundarbans. Maritime Studies 12: 7. https://doi.org/ 10.1186/2212-9790-12-7.

Issara Institute, and International Justice Mission (IJM). 2017. Not in the same boat: prevalence and patterns of labour abuse across Thailand's diverse fishing industry. Bangkok: Issara Institute and IJM.

Jackson, Bethany. 2019. Slavery from space: a remote sensing approach to ending modern slavery. https://delta87.org/2019/03/slaveryspace-remote-sensing-approach-ending-modern-slavery/ Accessed 7 March 2019.

Jackson, Bethany, and Jessica L. Decker Sparks. 2020. Ending slavery by decarbonisation? Exploring the nexus of modern slavery, deforestation, and climate change action via REDD+. Energy Research \& Social Science 69: 101610. https://doi.org/10.1016/j.erss.2020. 101610.

Jackson, Bethany, Kevin Bales, Sarah Owen, Jessica Wardlaw, and Doreen S. Boyd. 2018. Analysing slavery through satellite technology: how remote sensing could revolutionise data collection to help end modern slavery. Journal of Modern Slavery 4 (2): 169-199.

Jackson, Bethany, Jessica L. Decker Sparks, Chloe Brown, and Doreen S. Boyd. 2020. Understanding the co-occurrence of tree loss and modern slavery to improve efficacy of conservation actions and policies. Conservation Science and Practice. https://doi.org/10.1111/csp2. 183.

Jalais, Annu. 2004. People and tigers: an anthropological study of the Sundarbans of West Bengal, India. London School of Economics and Political Science, University of London. http://etheses.lse.ac.uk/ 1766/1/U194687.pdf

Jensen, Kari B. 2013. Child slavery and the fish processing industry in Bangladesh. Focus on Geography 56 (2): 54-65.

Kavvada, Argyro, Graciela Metternicht, Flora Kerblat, Naledzani Mudau, Marie Haldorson, Sharthi Laldaparsad, Lawrence Friedl, Alex Held, and Emilio Chuvieco. 2020. Towards delivering on the sustainable development goals using earth observations. Remote Sensing of Environment 247: 111930. https://doi.org/10.1016/j.rse.2020. 111930.

Kay, Susan, John Caesar, and Tamara Janes. 2018. Marine dynamics and productivity in the Bay of Bengal. In Ecosystem services for wellbeing in deltas, ed. Robert J. Nicholls, Craig W. Hutton, W. Neil Adger, Susan E. Hanson, Md. Munsur Rahman, and Mashfiqus Salehin, 263-275. Cham: Palgrave Macmillan. https://doi.org/10. 1007/978-3-319-71093-8.

Kibria, Abu S.M.G., Robert Costanza, Colin Groves, and Alison M. Behie. 2018. The interactions between livelihood capitals and access of local communities to the forest provisioning services of the Sundarbans Mangrove Forest, Bangladesh. Ecosystem Services 32: 41-49. https://doi.org/10.1016/j.ecoser.2018.05.003.

Kurekin, Andrey A., Benjamin R. Loveday, Oliver Clements, Graham D. Quartly, Peter I. Miller, George Wiafe, and Kwame Adu Agyekum. 2019. Operational monitoring of illegal fishing in Ghana through exploitation of satellite Earth observation and AIS data. Remote Sensing 11 (3): 293. https://doi.org/10.3390/rs11030293.

Landman, Todd. 2018. Out of the shadows: trans-disciplinary research on modern slavery. Peace Human Rights Governance 2 (2): 143-162. https://doi.org/10.14658/pupj-phrg-2018-2-1.

Landman, Todd, Zoe Trodd, Hannah Darnton, Davina Durgana, Kilian Moote, Paul Jones, Chloe Setter, Nadya Bliss, Sharlena Powell, and James Cockayne. 2019. Code 8.7: conference report. New York, NY: United National University. https://delta87.org/2019/03/code8-7-introduction/ accessed 12 February 2020. 
Lega, M., C. Ferrara, G. Persechino, and P. Bishop. 2014. Remote sensing in environmental police investigations: aerial platforms and an innovative application of thermography to detect several illegal activities. Environmental Monitoring and Assessment 186 (12): 82918301. https://doi.org/10.1007/s10661-014-4003-3.

Li, Xiaodong, Giles M. Foody, Doreen S. Boyd, and Feng Ling. 2019. Aging brick kilns in the Asian brick belt using a long time series of Landsat sensor data to inform the study of modern day slavery. Japan: IEEE International Geoscience and Remote Sensing Symposium (IGARSS). https://doi.org/10.1109/IGARSS.2019. 8898981.

Lucas, Richard, Alma Vázquez Lule, María Teresa Rodríguez, Muhammad Kamal, Nathan Thomas, Emma Asbridge, and Claudia Kuenzer. 2017. Spatial ecology of mangrove forests: a remote sensing perspective. In Mangrove ecosystems: a global biogeographic perspective, ed. Victor H. Rivera-Monroy, Shing Yip Lee, Erik Kristensen, and Robert R. Twilley, 87-112. Cham: Springer Nature, Cham. https:// doi.org/10.1007/978-3-319-62206-4.

Lynch, Jim, Mark Maslin, Heiko Balzter, and Martin Sweeting. 2013. Choose satellites to monitor deforestation. Nature 496: 293. https:// doi.org/10.1038/496293a.

Maligalig, Dalisay S., Sining Cuevas, and Aleli Rosario. 2009. Informal employment in Bangladesh. In $A D B$ economics working paper series 155. Manila: Asian Development Bank.

Masó, Joan, Ivette Serral, Cristina Domingo-Marimon, and Alaitz Zabala. 2019. Earth observations for sustainable development goals monitoring based on essential variables and driver-pressure-state-impactresponse-indicators. International Journal of Digital Earth 13 (2): 217-235. https://doi.org/10.1080/17538947.2019.1576787.

McGoogan, Cara, and Muktadir Rashid. 2016. Satellites reveal 'child slave camps' in UNESCO-protected park in Bangladesh. The Telegraph. https://www.telegraph.co.uk/technology/2016/10/23/ satellites-reveal-child-slave-camps-in-unesco-protected-park-in/ accessed 23 October 2016.

Molinari, Nicole. 2017. Intensifying insecurities: the impact of climate change on vulnerability to human trafficking in the Indian Sundarbans. Anti-Trafficking Review 8. https://doi.org/10.14197/ atr.20121784

Øhlenschlæger, Mia, Sarah C.B. Christensen, Henrick Bregnhøj, and Hans-Jørgen Albrechtsen. 2016. Submerged pond sand filter-a novel approach to rural water supply. Water 8: 1-14. https://doi. org/10.3390/w8060250.

Oozeki, Yoshioki, Denzou Inagake, Tsutomu Saito, Makoto Okazaki, Ippei Fusejima, Makoto Hotai, Tomowo Watanabe, Hiroya Sugisaki, and Masanori Miyahara. 2018. Reliable estimation of IUU fishing catch amounts in the northwestern Pacific adjacent to the Japanese EEZ: potential for usage of satellite remote sensing images. Marine Policy 88: 64-74. https://doi.org/10.1016/j.marpol. 2017.11.009.

Ottinger, Marco, Clauss Kersten, and Claudia Kuenzer. 2018. Opportunities and challenges for the estimation of aquaculture production based on Earth observation data. Remote Sensing 10: 1076. https://doi.org/10.3390/rs10071076.

Payo, Andres, Anirban Mukhopadhyay, Sugata Hazra, Tuhin Ghosh, Subhajit Ghosh, Sally Brown, Robert J. Nicholls, Lucy Bricheno, Judith Wolf, Susan Kay, Attila N. Lázár, and Anisul Haque. 2016. Projected changes in area of the Sundarban mangrove forest in Bangladesh due to SLR by 2100. Climatic Change 139 (2): 279 291. https://doi.org/10.1007/s10584-016-1769-z.

Pettorelli, Nathalie, Henrike Schulte to Bühne, Ayesha Tulloch, Grégoire Dubois, Cate Macinnis-Ng, Ana M. Queirós, David A. Keith, Martin Wegmann, Franziska Schrodt, Marion Stellmes, Ruth Sonnenschein, Gary N. Geller, Shovonial Roy, Ben Somers, Nicholas Murray, Lucie Bland, Ilse Geijzendorffer, Jeremy T. Kerr, Stefanie Broszeit, Pedro J. Leitão, Clare Duncan, Ghada El Serafy, Kate S. He, Julia L. Blanchard, Richard Lucas, Paola
Mairota, Thomas J. Webb, and Emily Nicholson. 2018. Satellite remote sensing of ecosystem functions: opportunities, challenges and way forward. Remote Sensing in Ecology and Conservation 4 (2): 71-93. https://doi.org/10.1002/rse2.59.

Pham, Tien Dat, Naoto Yokoya, Dieu Tien Bui, Kunihiko Yoshino, and Daniel A. Friess. 2019. Remote sensing approaches for monitoring mangrove species, structure, and biomass: opportunities and challenges. Remote Sensing 11 (3): 230. https://doi.org/10.3390/ rs 11030230

Planet Team. 2018. Planet application program interface: In space for life on Earth. Planet Labs, San Francisco, CA. https://api.planet.com

Planet Team. 2019. Planet announces more spectral bands, $50 \mathrm{~cm}$ resolution, global analytics, and change detection. Planet Labs. www. planet.com/pulse $/$ more-spectral-bands- $50 \mathrm{~cm}$-global-analyticschange-detection/ Accessed 2 January 2020.

Popkin, Gabriel. 2016. Satellite alerts track deforestation in real time. Nature 530: 392-393. https://doi.org/10.1038/530392a.

Prasad, Kumar Arun, Marco Ottinger, Chunzhu Wei, and Patrick Leinenkugel. 2019. Assessment of coastal aquaculture for India from Sentinel-1 SAR time series. Remote Sensing 11: 357. https:// doi.org/10.3390/rs11030357.

Rahman, Abdullah F., Danilo Dragoni, and Bassil El-Masri. 2011. Response of the Sundarbans coastline to sea level rise and decreased sediment flow: a remote sensing assessment. Remote Sensing of Environment 115 (12): 3121-3128. https://doi.org/10.1016/j.rse. 2011.06.019.

Rahman, Md. Mizanur, Md. Nabiul Islam Khan, A.K. Fazlul Hoque, and Imran Ahmed. 2015. Carbon stock in the Sundarbans mangrove forest: spatial variations in vegetation types and salinity zones. Wetlands Ecology and Management 23 (2): 269-283. https://doi. org/10.1007/s11273-014-9379-x.

Rahman, M.D., M. Ashraful Mojibar, Shahroz Mahean Haque Islam, and Abdul Wahab. 2017. Mud crab aquaculture and fisheries in coastal Bangladesh. World Aquaculture: 47-52.

Ramsar. 2003. Sundarbans reserved forest. https://rsis.ramsar.org/ris/ 560?language =en Accessed 17 January 2019.

Richards, Daniel R., and Daniel A. Friess. 2016. Rates and drivers of mangrove deforestation in Southeast Asia, 2000-2012. PNAS 113 (2): 344-349. https://doi.org/10.1073/pnas.1510272113.

Saif, Samia, and Douglas Craig MacMillan. 2016. Poaching, trade, and consumption of tiger parts in the Bangladesh Sundarbans. In The geography of environmental crime: conservation, wildife crime and environmental activism, ed. Gary R. Potter, Angus Nurse, and Matthew Hall, 13-32. London: Palgrave Macmillan.

Sankaran, Krishnaswamy. 2019. Protecting oceans from illicit oil spills: environment control and remote sensing using spaceborne imaging radars. Journal of Electromagnetic Waves and Applications 33 (18): 2373-2403. https://doi.org/10.1080/09205071.2019.1685409.

Scoles, Sarah. 2019. Researchers spy signs of slavery from space. Science. https://doi.org/10.1126/science.aax0751.

Sparks, Jessica L. 2018. Social conflict on the seas: links between overfishing-induced marine fish stick declines and forced labor slavery. Environmental Justice Department University of Denver, Denver, CO. https://digitalcommons.du.edu/etd/1473

Suresh, Merugu, and Kamal Jain. 2013. Change detection and estimation of illegal mining using satellite images. Proceedings of 2 nd International Conference on Innovations in Electronics and Communication Engineering (ICIECE-2013), Hyderabad: 246-251.

Tickler, David, Jessica J. Meeuwig, Katherine Bryant, Fiona David, John A.H. Forrest, Elise Gordon, Jacqueline Joudo Larsen, Beverly Oh, Daniel Pauly, Ussif R. Sumaila, and Dirk Zeller. 2018. Modern slavery and the race to fish. Nature Communications 9 (1): 4643. https://doi.org/10.1038/s41467-018-07118-9.

United Nations. 2016. Transforming our world: the 2030 agenda for sustainable development. New York, NY, United Nations General Assembly. A/RES/70/1. 
United States Geological Survey. 2003. Preliminary assessment of the value of Landsat 7 ETM+ data following scan line corrector malfunction. USGS.

Verité. 2016. Research on indicators of forced labor in the supply chain of shrimp in Bangladesh. Amherst, MA: Verité.

Verité. 2017. Strengthening protections against trafficking in persons in federal and corporate supply chains: research on risk in 43 commodities worldwide. Amherst, MA: Verité.

Walk Free. 2018. The 2018 global slavery index. 4th ed. Perth, WA: Minderoo Foundation.

Woellert, Kirk, Ehrenfreund Pascale, Antonio J. Ricco, and Henry Hertzfeld. 2011. Cubesats: cost-effective science and technology platforms for emerging and developing nations. Advances in Space Research 47 (4): 663-684. https://doi. org/10.1016/j.asr.2010.10.009.

Young, Darrell L. 2019. Detection of illegal fishing. Proceedings of SPIE Geospatial Informatics $I X$ (SPIE Defense and Commercial Sensing, Baltimore, MD, May 2019) 10992: 109920B. https://doi.org/10. $1117 / 12.2520091$

Publisher's note Springer Nature remains neutral with regard to jurisdictional claims in published maps and institutional affiliations. 